Smith, Adam. 2002. Teoria dos sentimentos morais. São Paulo: Martins Fontes.

\author{
Denise dos Santos Rodrigues \\ Doutora em Ciências Sociais - UERJ, e Doutoranda em Filosofia - UERJ, \\ e-mail: denise.rodrigues@oi.com.br
}

Recebido: $17 / 05 / 2012$

Aceito: 11/10/2012

\title{
Simpatia e espectador imparcial: conceitos fundamentais para uma leitura da Filosofia Moral de Adam Smith
}

\author{
Sympathy and impartial spectator: essential concepts for a reading of Adam Smith's Moral Philosophy
}

Certamente Adam Smith (1723-1790) é muito mais lembrado por suas incursões no campo da economia do que no campo da Filosofia Moral. Em 1759 publicou a primeira edição da sua Teoria dos Sentimentos Morais (ou Ensaio para uma análise dos princípios pelos quais os homens naturalmente julgam a conduta e o caráter, primeiro de seus próximos, depois de si mesmos), um texto que teve várias alterações até a sexta e última edição, em 1790 , meses antes da morte de seu autor. Dividido em sete partes, teve seu conteúdo importado de notas de seu curso de Filosofia Moral na Universidade de Glasgow, tendo como objetivo a investigações sobre princípios morais, buscando compreender como é possível saber qual é o modo correto de agir. Ou, nos seus termos, classificar aquilo que é "[...] objeto de aprovação, honra e recompensa e o outro dede vergonha, censura e castigo [...]" (TSM, P.VII, S.I: 333). Para isso, Smith trilhou seu caminho tomando como referência duas questões: 1) no que consiste a virtude, compreendida como temperamento e modelo de conduta que resultam em aprovação; e 2) o que leva a o indivíduo a preferir uma conduta a outra. Isto o insere num debate entre empiristas e racionalistas, com posições bastante divergentes. Os primeiros tentam responder essas questões com base na experiência, mais precisamente das ocorrências da vida em sociedade. Nessa perspectiva, os juízos morais não estariam subordinados à razão, como supunham os racionalistas. Para estes, a razão é que seria a grande encarregada de discernir entre o bem e o mal, indicando as mais louváveis formas de proceder. Se o empirista Hume, seu amigo, recusou a influência da razão sobre as paixões ou ações, Smith ponderou essa proposição, aceitando que a razão participa, de certa forma, da formulação de regras morais válidas para efetuar uma escolha ente as formas mais adequadas de conduta. Isso ocorre indutivamente, do ponto de vista desse autor, quando o indivíduo recorre a percepções primárias sobre acontecimentos que lhe agradam ou desagradam, moldando seu padrão ideal de conduta. Então, Adam Smith aborda, nessa obra, como é possível conhecer a fundamentação da moral, uma proposta teórica onde se destacam conceitoschave como simpatia e espectador imparcial, entre outros que selecionamos para essa resenha.

Simpatia é um conceito fundamental presente no Tratado da Natureza Humana (1738) de David Hume, definido como uma qualidade da natureza humana que vincula as pessoas umas às outras. Adam Smith tomou-o emprestado, colocando-o como base da vida moral. No entanto, convém ressaltar que este conceito tem um significado muito amplo, o que permite uma multiplicidade de interpretações ao longo do texto. Se recorremos à etimologia. Temos o radical syn, equivalente a "junto"; e patos, que indica "sentimento". Do latim, simpathia, indica "comunhão de sentimentos"; do grego sympatheia, "capacidade de sentir o mesmo que outro". Do inglês, empathetic é aquele que compreende o outro, mas nem sempre 
esse termo se apresenta como versão mais apropriada em Adam Smith para o conceito de simpatia (sympathetic). Por vezes, pode ser compreendido como "empatia", traduzida como correspondência com os sentimentos do outro (TSM, P.I, S.I, III: 16), mas em geral sympathetic é traduzido como sinônimo de compassivo, compreensivo, favorável. Nesse texto, especificamente, interpretamos simpatia como o compartilhamento de um sentimento, o que abrange tanto a paixão quanto a situação que a provoca (TSM, P.I, S.I, I: 9). Pode ser remetido, ainda, à compaixão ou à solidariedade, sendo definido por Adam Smith nos seguintes termos:

Simpatia, embora talvez originalmente sua significação fosse a mesma, pode agora ser usada, sem grande impropriedade para denotar nossa solidariedade com qualquer paixão [...] (TSM, P.I, S.I, I: 8).

Simpatia indica, em geral, que há uma afinidade ou consonância entre os sentimentos do ator e do espectador - este internalizado através de nossa imaginação -, que os julga adequados ou inadequados a um determinado contexto. Se simpatizamos, aprovamos; se antipatizamos, rejeitamos.

Aprovar ou desaprovar opiniões alheias significa observar sua concordância ou discordância com suas próprias ações, o que também ocorre no terreno dos sentimentos, emoções, afetos ou paixões (TSM, P.I, S.I, III: 16). Dessa perspectiva simpatia se mostra como um princípio norteador que aflora numa determinada ocasião, gerando aprovação ou desaprovação moral. Aquele que observa se sensibiliza com o outro, imaginando as sensações que antecederam sua expressão. Não podemos esquecer que aqui temos uma via de mão dupla, uma vez que, além desse compartilhamento de paixões há, ainda, o desejo de aprovação, de reconhecimento do indivíduo que sofre. $\mathrm{O}$ estabelecimento de laços fundados na simpatia, portanto, aumenta a segurança do indivíduo, criando uma convivência mais harmoniosa.

Adotando uma perspectiva fortemente realista, Smith entende que o ser humano não é um animal, dessa forma, necessita da companhia de outros, mas só obtém colaboração devido ao cálculo embutido no interesse próprio. Ele observa os traços de uma natureza humana imutável, atravessada por paixões sensíveis particulares como a raiva e a inveja; pelo amor-próprio, ou mais especificamente o egoísmo, pela benevolência e pela consciência, que é a razão que orienta o cálculo racional de custos e benefícios da forma mais adequada de agir. Convém ressalatar que, como já mencionado, embora Smith reconheça que a razão influencia a formulação das regras gerais da moralidade, importantes para a harmonia da vida social, são os afetos que predominam, ou seja, as regras partem das percepções primárias do que é certo ou errado (TSM, L.VII, S.III, III: 399). Os variados sentimentos humanos, que resultam em atos, não são bons ou ruins em si mesmos. Alguns deles, como o amor-próprio, por exemplo, impõe o cuidado de si mesmo:

[...] todo homem está muito mais profundamente interessado no que diz respeito imediatamente a si, do que no que diz respeito a outro homem qualquer [...] (TSM, P. II, S.II, II: 103).

Cuidado de si é um conceito utilizado por Michel Foucault em curso ministrado no Collége de France, entre 1981 e 1982, posteriormente publicado como "A Hermenêutica do Sujeito". Muito antes Adam Smith o aplicou tendo como significado a consciência da necessidade de autopreservação, portanto, da vida saudável de cada um, o que se exprime na busca da satisfação dos apetites e na experimentação de sensações boas ou ruins que norteiam o comportamento humano. Ratificamos, aqui, que a racionalidade é a principal responsável pela busca dos meios para satisfação das necessidades primárias, pela conquista do prazer e pelo afastamento da dor. Esse cuidado de si, incluindo a satisfação de necessidades e conveniências, buscando benefícios - é orientado por condições exteriores propícias a determinado tipo de vida, a fortuna externa. Essa fortuna, que pode proporcionar vantagens ao homem, depende da obtenção do crédito de outros, do respeito e da posição de cada um, que é o que garante a segurança, reduzindo os riscos, os conflitos. Esse respeito pelo outro, traduzido sob a forma de aceitação pública, depende da simpatia que as pessoas desenvolvem entre si (TSM, P. VI, S.I: 265), conceito que será mais bem elaborado adiante.

O cuidado de si, que inclui aspectos como saúde, reputação, posição, reconhecimento, fortuna no sentido de riqueza, depende teoricamente da virtude da prudência, que varia em graus e reduz os riscos, aumentando a segurança. Uma vez que a sensação de derrota é sempre mais intensa que a da vitória, a segurança é de suma importância. Em temos práticos, o homem prudente é aquele que congrega um elenco de características que interferem diretamente na sua vida social, gerando sua aceitação pelo grupo. Entre elas destacamos, por exemplo, a aquisição de conhecimentos sólidos no campo profissional, a habilidade com os negócios, a constância, a frugalidade e a parcimônia nas despesas. Aquele que é prudente, o que pode ser interpretado como um tipo ideal (do alemão idealtyp) ou tipo puro, conceito 
associado a Max Weber, não quer impor-se a qualquer custo, nem persuadir (TSM, P. VI, S.I: 266). Ele não é arrogante, mas simples, modesto, correto, não aprova aqueles que não agem com prudência, ou seja, os que diferem daquilo que ele espelha. Ele não valoriza as trocas de pequenos favores, mas, quando o faz, é unicamente em sua defesa. Ele é sincero, mas nem sempre franco e aberto. Ainda que diga a verdade, é sempre criterioso, reservado no discurso. Ele é, ainda, sensível e amigo, mas essa amizade difere da afeição apaixonada, transitória, mas sossegada, fiel, seletiva, constituída pela admiração mútua, estima, solidariedade, discrição (TSM, P. VI, S.I: 267). O homem prudente não é um orador brilhante, mas inofensivo, que detesta a petulância, a grosseria, a impertinência. Ele é decente, escrupuloso, respeitoso, o exemplo de homem de talentos e virtuoso (TSM, P. VI, S.I: 268). Smith explica que o sacrifício do conforto é, às vezes, necessário ao homem prudente, amplamente aprovado.

Smith tenta resumir sua explanação afirmando que a prudência, nos termos assim especificados, não é considerada uma das virtudes mais caras ou nobres. Ela conquista certa estima fria, mas não parece ter direito a um ardente amor e admiração (TSM, P. VI, S.I: 269-270). Essa prudência é definida como a conduta sábia e judiciosa que pode ser orientada para os cuidados mais nobres que os de si. Para o autor, a prudência também pode designar uma prudência superior, sinônimo de perfeição, indicando arte, talento ou disposição para agir. Trata-se da extrema perfeição de todas as virtudes morais e intelectuais, unindo cabeça e coração, o caráter do homem sábio (TSM, P. VI, S.I: 270). Smith menciona, ainda, figuras que podem ser consideradas como virtuosas, entre as quais se destacam os estadistas, generais, legisladores, que também apresentam características como valor, benevolência, respeito a regras de justiça e autodomínio.

Em contraposição à prudência, Smith menciona a imprudência, que é a incapacidade de cuidar de si, podendo ser objeto de compaixão ou desprezo, mas nunca objeto de ódio ou indignação. Se combinada com vícios, então resulta em degradação, podendo gerar até o ódio universal, punição. Segundo o autor, se a injustiça é a mesma para todos, aplicada da mesma forma em todos os lugares, o mesmo não ocorre com a imprudência, cuja percepção varia conforme o local (TSM, P. VI, S.I: 270). Nesse sentido, Smith cita Maquiavel, criticando sua moralidade que, segundo ele, não era “das mais encantadoras". Refere-se, aqui à conduta de César Bórgia, nobre calculista, violento, que preparou uma emboscada para seus inimigos em 31 de dezembro de 1502. Convidou-os para seu palácio, aprisionou-os e, depois, assassinou-os. Esse fato foi tratado, por Maquiavel, como habilidade na condução de assuntos estratégicos, desprezando o que Smith destaca como "[...] a ingenuidade e fraqueza dos sofredores, sem compaixão ou indignação pela falsidade do executor [...]" (Smith, 2002: 457). César Bórgia, educado para ser um homem da igreja, como seu pai, mas que teve um percurso totalmente diferente. Abandonou a carreira eclesiástica tendo como desculpa a substituição do irmão, João, capitão das forças militares do papado. Tornou-se Duque em 1498 e tentou constituir um principado. Acabou sendo preso após a morte do pai, mas escapou, morrendo aos 31 anos na Espanha. Com esse exemplo, Smith acusou Maquiavel de tratar a violência e a injustiça com admiração reforçando que, em determinados contextos, um homem hábil, perverso, indigno, muitas vezes passa pelo mundo com muito mais mérito que merece, ao contrário do tolo, que desperta ódio e desprezo (TSM, P. VI, S.I: 272). Nos termos de Adam Smith

[...] a prudência, somada com outras virtudes, constitui o maior dos caracteres, a imprudência, combinada com outros vícios, constitui o mais vil [...] (TSM, P. VI, S.I: 272).

Para Adam Smith, mais que suprir suas necessidades de sobrevivência, ou seja, zelar por sua autopreservação, o homem busca usufruir das vantagens que a fortuna externa pode trazer. Entre os mais fortes dos desejos humanos, convém ressaltar, estão o mérito e o reconhecimento que, do ponto de vista de um indivíduo considerado virtuoso, deveriam ser decorrentes unicamente do caráter humano, da sua conduta (TSM, P. VI, S.I: 266), mas nem sempre é assim, o que é mostrado pela história da humanidade, de onde se pode extrair vários exemplos.

A observação das situações, a experiência, é de grande relevância em Adam Smith. Ela gera impressões, desperta sentimentos diferenciados, de acordo com a proximidade. Isso ocorre porque ao indivíduo importa mais a sua própria felicidade do que a da humanidade; portanto, ele não se sensibiliza tanto com tudo aquilo que está distante. Dessa forma, ocorrências com indivíduos que não fazem parte das suas relações privadas não o afetam diretamente. De acordo com Smith, no entanto, por mais egoísta que alguém seja, há “[...] alguns princípios em sua natureza que o fazem interessar-se pela sorte de outros, e considerar a felicidade deles necessária para si mesmo [...]" (TSM, P.I, S.I, I, I: 5). Isso acontece quando, através da imaginação - que é um instrumento relevante na teoria moral de Adam Smith - o indivíduo entra em consonância com os sentimentos alheios. A 
imaginação é que permite ao indivíduo tentar conhecer e analisar as motivações da ação do outro se colocando no seu lugar conforme o senso de conveniência. Segundo o autor, uma vez que não podemos sair de nossa própria pessoa, é difícil mesurar o sofrimento do outro. Assim, somente a imaginação nos permite conceber parte das sensações (TSM, P.I, S.I, I: 6).

A mobilização da imaginação para avaliar como o outro se sente diante de tal acontecimento ratifica, na teoria smithiana, que é impossível acessar diretamente o que o outro sente. Só contamos com circunstâncias e comportamentos observáveis; cabendo à imaginação a suposição do que um indivíduo sentiria se estivesse no lugar do outro, identificando-se com sua dor ou prazer, o que lhe permitiria um julgamento imparcial de certa conduta, remetidas às normas vigentes. Smith coloca, assim, a imaginação como instrumento eficiente para demonstrar como juizos éticos são formados em um contexto onde as normas são construidas socialmente, são convenções resultantes da vida em sociedade, o que torna a vida social a fonte da moralidade.

Smith reconhece que há sentimentos, afeições e desafeições que residem na alma humana, mas tenta afastar-se desse campo para efetuar uma avaliação moral imparcial, em busca de um julgamento justo. Esse distanciamento é concretizado, em Adam Smith, através da apresentação do espectador imparcial (impartial spectator), emblemático da capacidade de auto-refletividade, aquela que apreende e pondera julgamentos considerando o conjunto dos elementos envolvidos num acontecimento. De fato, ao instituir esse recurso Smith não contempla apenas um espectador externo, mas também interno, que define como o "[...] o homem dentro do peito - o grande juiz e árbitro de suas condutas [...]" (TSM, P.III, II: 159). Trata-se, então, do próprio eu de cada indivíduo, observador de si e dos outros, aquele que estabelece um diálogo com sua própria consciência para poder julgar. Conforme Smith, o espectador imparcial é aquele que nos mostra

[...] o que nos diz respeito em sua forma e dimensões apropriadas; ou que poderemos estabelecer uma comparação apropriada entre nossos interesses e os de outras pessoas [...] (TSM, P.III, III: 164).

Esse tipo ideal, para recorrer aos termos de Max Weber, personifica a transferência imaginária de um para o lugar do outro, mas sempre considerando o amor-próprio, convém ressaltar. Dessa forma consegue observar e julgar também a si mesmo e, em busca de aprovação social e, daí, tenta moderar suas atitudes. Numa sociedade de espectadores imparciais, um pode servir de espelho para o outro, expondo elementos como sentimentos, atitudes, motivações, que proporcionam o autoconhecimento e a sinalização de ações que geram ou não aprovação.

Para aquele que recorre ao espectador imparcial para efetuar seus julgamentos, presente e passado se igualam, embora para alguns esses dois tempos possam parecer diferentes. De fato, o espectador imparcial valoriza o esforço adequado de autodomínio, que permite que a pessoa modere suas ações no presente vislumbrando as consequências delas no futuro (TSM, P.VI, S.I: 268). Essa prática do autodomínio pode ser representada pela abstenção do prazer imediato, merecendo, portanto, a estima e consideração dos outros. Smith desenvolve uma longa descrição do homem prudente, moderado, que inclui aquele que sabe administrar sua vida financeira, vivendo de acordo com sua renda, sendo criterioso nos seus investimentos. Esse homem não assume encargos que não pode cumprir, não se intromete em assuntos alheios, nem emite pareceres não solicitados, não demonstra influência para resolver uma situação, não participa de disputas acirradas, não compartilha de jogos de ambições e nem se integra a facções. Ele não se recusará a servir seu país, mas não é esse seu objetivo e, assim, não se empenhará para que outros o aceitem naquela posição (TSM, P. VI, S.I: 269).

$\mathrm{O}$ indivíduo, em contato com sua consciência, manifesta " $[. .$.$] a serenidade e o autodomínio que$ constituem a dignidade de toda paixão, e que a reduzem àquilo de que os demais podem partilhar [...]" (TSM, P.I, S.I, V: 25). Esse autodomínio (selfcommand) pode ser representado através de outro tipo ideal, que é o homem prudente, aquele que age com autocontrole, que tem domíno de sua vida, de suas reações, que age de acordo com a moralidade vigente para obter aprovação dos semelhantes. Entretanto, convém ressaltar que, assim como nem sempre um indivíduo consegue se colocar no lugar do outro, sentir suas emoções na mesma intensidade, nem sempre o indivíduo alcança o autodomínio. No entanto, a observação participante da vida em sociedade, a experimentação, permite que o indivíduo identifique o que pode ou não fazer, o que pode ofender o outro. Conhecer a subjetividade humana, os direitos de cada um e das instituições que existem para assegurá-los é imprescindível para viver em sociedade. A moderação de certas atitudes aumenta o grau de aprovação na sua comunidade e melhorando sua convivência.

Como nem todos os homens conseguem ter um comportamento social ideal, para promover a felicidade geral, a justiça, como esfera da vida social torna-se necessária, sendo mais importante que disposições da natureza humana, como a caridade, a generosidade e a amizade. Podemos dizer que há, 
assim, em Smith, uma instrumentalização individual que é reforçada com a instrumentalização do Estado, que dispõe da justiça - teoricamente a representação máxima da imparcialidade - para garantir o convívio harmônico entre indivíduos distintos. Segundo Smith, a justiça é:

[...] é o principal pilar que sustenta todo edifício. Se removida, a grande, imensa estrutura da sociedade humana, essa estrutura cuja instauração e suporte neste mundo parece ser exigido, se me permitem dizer, o peculiar e caro cuidado da natureza, deverá em pouco tempo esboroar em átomos [...] (TSM, P.II, S.II, III: 107-108).

Se cada homem tem direito igualmente à sua própria felicidade, não é admissível que um perturbe o outro ou julgue seu bem estar mais importante que o do outro. Nenhum espectador imparcial - medida da consciência de cada um - pode concordar com isso. Mas como a natureza humana é imprevisível, é preciso que haja um mecanismo de mediação, aqui representado pelo Estado. Assim, se o indivíduo falhar, o Estado intervém para assegurar o direito de cada um isoladamente, assim como da coletividade, impedindo que um viole o direito do outro, ou a propriedade do outro. A violação da propriedade do outro, que compreende a posse de si mesmo, se configura como um crime mais grave que a simples quebra de contrato, que apenas frustra o indivíduo.
Há leis destinadas a proteger as pessoas, suas posses, seus direitos pessoais (TSM, L.II, S.II, II: 104). A propriedade, que foi sinônimo de poder na Idade Média e que ganhou status equivalente ao da liberdade e igualdade na Revolução Francesa, foi considerada um direito natural, inalienável e imprescritível, consagrada no artigo 17 da Declaração dos Direitos do Homem e do Cidadão (1789). Smith acredita, como Locke, no seu Tratado sobre o Governo Civil, que a propriedade privada está fundada no trabalho pessoal, mas reconhece que o governo civil, encarregado da garantia dos direitos individuais, o é, de fato, para evitar os riscos aos quais os proprietários se expõem contra os não proprietários, o que é mais bem abordado em A Riqueza das Nações? Investigação sobre a natureza e suas causas. Enfim, de acordo com Adam Smith, uma vez que, através da simpatia e das avaliações do espectador imparcial um indivíduo se solidariza com aquele que foi prejudicado, ou seja, com o ressentimento nutrido por aquele cujo direito foi violado, são aguardadas punições para os culpados. Nessa perspectiva, é possível inferir, então, que a justiça, uma construção social, surge da simpatia com o ressentimento daquele que sofre e, ainda, do prazer pela punição do culpado, o que ressalta a importância da inviolabilidade dos direitos humanos como imposição para uma vida social harmônica (TSM, P.II, S.II, II: 104). 
